\title{
CHEST PHYSIOTHERAPY: \\ A PHYSIOLOGICAL ASSESSMENT DURING INTERMITTENT POSITIVE PRESSURE VENTILATION IN RESPIRATORY FAILURE ${ }^{\circ}$
}

\author{
A. K. LAws, B.SC., M.B., B.S., F.F.A.R.C.S., and \\ R. W. MCINTYRE, M.B., CH.B., D.A., F.R.C.P.(C) $†$
}

Chest PHYSIOTHERAPY has become accepted as an essential and valuable adjunct to the care of patients undergoing artificial ventilation for respiratory failure. Many centres where such patients are cared for include in their treatment programme regular sessions of chest physiotherapy, each of which may last for as long as an hour. Despite this widespread application to clinical medicine, the efficacy of this form of therapy and the occurrence and magnitude of any unwanted effects have been extremely poorly documented.

Oesophageal and tracheal pressure and expiratory flow during external compression and vibration of the chest have been reported. ${ }^{1}$ Other workers ${ }^{2}$ measured blood gas tensions in arterialized capillary blood of neonates receiving chest physiotherapy during artificial ventilation for tetanus and found an immediate fall in oxygen tensions, which after one hour had returned to pretreatment levels. Our particular interest in this subject was stimulated by the deaths of two patients during the course of treatment by the physiotherapist. The deaths occurred despite the fact that in our practice chest physiotherapy is not given to patients with an unstable cardiovascular system or to those in whom compensatory mechanisms are suspect. Other workers ${ }^{1}$ have stated that the fear of failure to maintain cardiac output hardly ever justified the omission of chest physiotherapy, even in patients who are very ill.

The purpose of this present work was twofold; firstly, to assess any improvement in gas exchange resulting from any one session of chest physiotherapy, and secondly, to measure the accompanying changes in cardiac output.

\section{METHODS}

In this study six patients were investigated; four of these were studied on two separate occasions. The age, sex, and diagnosis of each patient appear in Table I. All were in respiratory failure and were receiving controlled ventilation at constant tidal volume $(10-13 \mathrm{ml} / \mathrm{kg})$ without intermittent sighs. The ventilators used were either the Engström or the Ohio 560. Inspired oxygen tension was adjusted to give a clinically acceptable arterial oxygen tension, and all measurements were made using this inspired gas mixture.

Cardiac output was measured with a dye dilution technique using indocyanine green. Injection was into the superior vena cava, and withdrawal from a femoral artery through an indwelling arterial line and a Waters cuvette-densitometer

-Presented at the Annual Meeting, Canadian Anaesthetists' Society, Toronto, June 16, 1969.

†Department of Anaesthesia, University of Toronto, and the Toronto General Hospital. 
TABLE I

\begin{tabular}{cccl}
\hline Patient & Age & Sex & \multicolumn{1}{c}{ Diagnosis } \\
\hline 1 & 41 & F & $\begin{array}{l}\text { caesarean section, peritonitis, } \\
\text { aspiration pneumonitis } \\
\text { ligation of bleeding oesophageal } \\
\text { varices, empyema }\end{array}$ \\
3 & 63 & M & myocardial infarction, cardiac arrest \\
4 & 66 & M & myasthenia gravis \\
5 & 63 & M & drug overdosage \\
6 & 27 & lobectomy, postoperative pneumonia \\
\hline
\end{tabular}

system. Direct readout of cardiac output was obtained from a Waters co4 Cardiac Output Computer, calibrated for each patient. By the use of an efficient one-way valve, true expired gas was collected and gas compressed in the ventilator and tubing was vented at the expiratory port of the ventilator. Expired gas collection was over a period of five minutes and during this time inspired gas was sampled, arterial blood was drawn, and cardiac output was measured in duplicate. Mixed expired $\mathrm{CO}_{2}$ concentration was measured with a Beckman infrared analyser (LB2), and inspired and expired oxygen concentrations with a Beckman oxygen analyser (model E2). Blood gases were measured at $37^{\circ} \mathrm{C}$ with an Instrumentation Laboratories $\mathrm{pH} /$ gas analyser. Gas tensions were corrected to body temperature.

Alveolar values for oxygen and carbon dioxide were calculated using the measured values for inspired gas, mixed expired gas, and tidal volume, and an assumed value for anatomical dead space based upon body weight $(2.2 \mathrm{ml} / \mathrm{kg})$. Necessary adjustments to dead space were made for intubation, tracheostomy, and added dead space.

Arterial to alveolar tension gradients for both oxygen and carbon dioxide were derived and were used as a measure of the efficiency of gas exchange. Changes in both these parameters were used as an index of the efficacy of any therapeutic manoeuvre.

Initial measurements assessing gas exchange and cardiac output were made at least two hours after the previous session of physiotherapy. Chest physiotherapy was then begun. This lasted approximately thirty minutes. During this time serial measurements of cardiac output were made. Thirty minutes after the completion of physiotherapy, after the re-establishment of steady-state conditions, gas exchange and cardiac output were again measured.

A number of procedures constitute what is usually called chest physiotherapy. These include postural drainage in association with external manual pressure applied to the chest on expiration, using shaking or vibration. Sometimes the physiotherapist may precede this with clapping percussion to the chest wall. "Artificial cough" is also produced by synchronizing powerful chest compression and vibration with expiration following each of a series of big breaths (20-25 $\mathrm{ml} / \mathrm{kg}$ ). The big breath may be delivered by the ventilator or by hand from an inflating bag. All these manoeuvres are followed by tracheobronchial suction.

In this study, chest physiotherapy consisted of expiratory vibrations at usual tidal volumes, six artificial coughs in the supine position, and six in each of the left and right lateral positions. 


\section{Results AND Discussion}

The arterial to alveolar gradients for carbon dioxide and oxygen for each patient appear graphically in Figures 1 and 2. In this group of patients given chest physiotherapy in the way described, any one session of treatment resulted in no overall reduction of gradients. This implies that there was no improvement in the efficiency of pulmonary gas exchange and that the conditions resulting in venoarterial shunting in some regions of the lung and in overventilation of others were not affected in any lasting manner by physiotherapy.

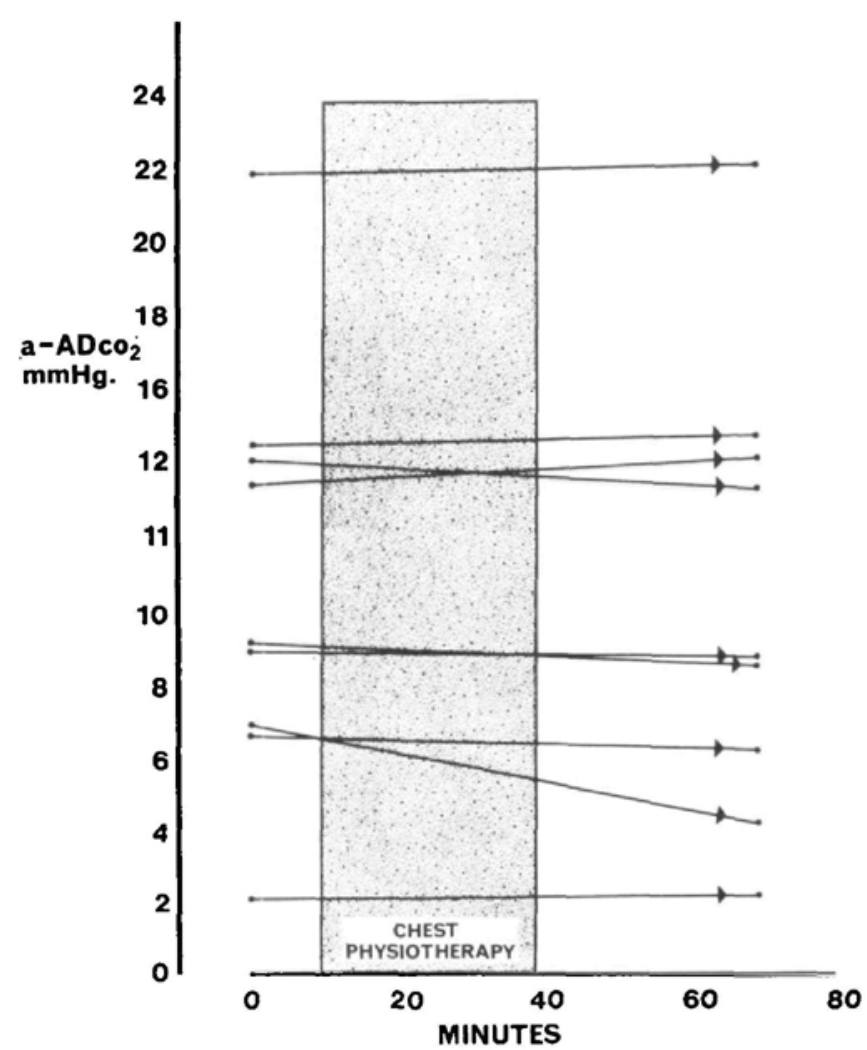

Figure 1. Changes in arterial-alveolar gradients for carbon dioxide following chest physiotherapy.

The rationale of many of the techniques of physiotherapy is based on the elimination of retained sputum. In patients receiving intensive care, where position is changed frequently, when inspired gases are adequately humidified and tracheobronchial toilet is performed frequently, sputum retention is seldom a problem. Yet techniques aimed at sputum removal are still applied to these patients. None of the patients studied had large amounts of sputum and therefore it is perhaps to be expected that no improvement in gas exchange was demonstrated.

It is well known that patients with artificial airways are unable to cough effectively; therefore such patients receive a series of "artificial coughs." It has been 
claimed $^{1}$ that external chest compression squeezes out secretions from completely occluded airways by direct lung compression. It would seem that the degree of direct lung compression needed to do this would produce areas of collapse with accompanying shunt. In fact, it is important that the physiotherapist should not aim to expel from the chest a volume greater than that inspired, thus avoiding reducing an already low FRC even further.

More recently, effective coughing of small airways has been attributed to dynamic closure of airways. ${ }^{3}$ This requires some expansion of lung units distal to the

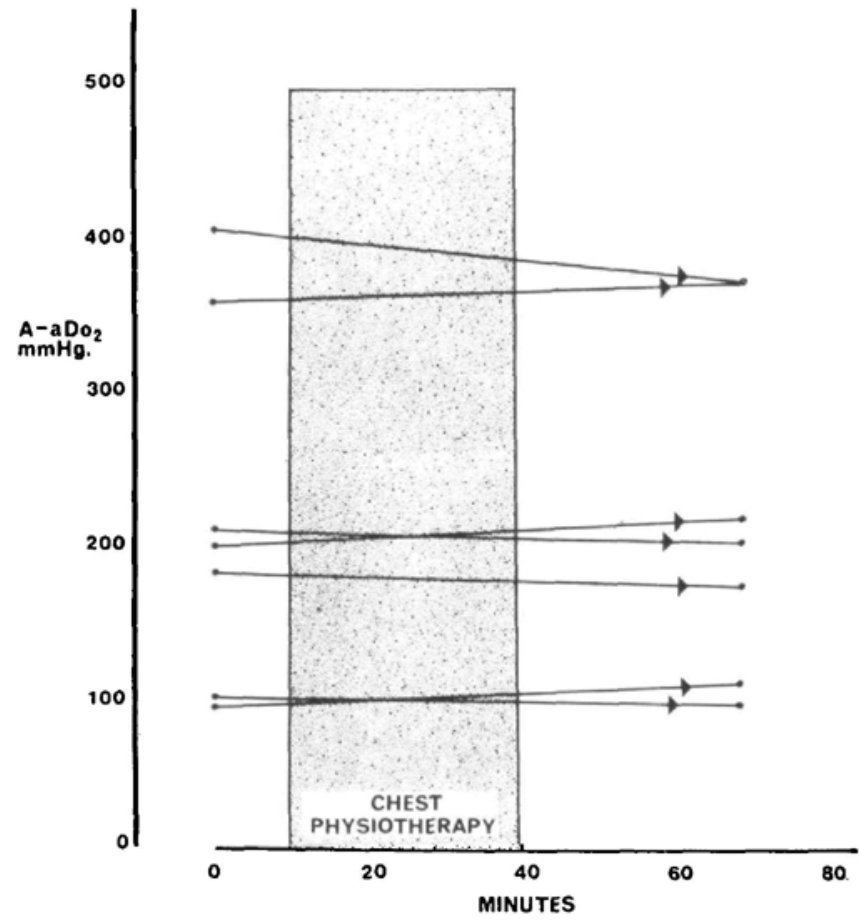

Figure 2. Changes in alveolar-arterial gradients for oxygen following chest physiotherapy.

airways to be cleared and high expiratory flows from these areas. It seems unlikely that the hyperinflations (which form the first part of an artificial cough) can achieve direct ventilation of a lung region with a completely occluded airway. Indirect ventilation of such regions by collateral channels seems the most probable mechanism. Increased expiratory flows are provided by the physiotherapist by applying chest compression synchronized with expiration. Whether flows high enough to result in dynamic closure and effective cough can be achieved in this way is still not known.

In Figure 3 the results of the cardiac output estimations for each patient are presented graphically. The cardiac output before treatment is recorded as 100 per cent, and the outputs showing maximal change during physiotherapy and those 30 minutes later are recorded as a percentage change of this initial value. The response observed was either a rise or a fall by as much as 50 per cent. In each 
patient the change persisted to a lesser degree up to 15 minutes after the completion of physiotherapy. By 30 minutes cardiac outputs had returned to approximately pre-treatment values.

The maximal changes in cardiac output were observed during hyperinflations with vigorous chest compression and vibration. In those patients who were unconscious or too ill to resist the physiotherapist's efforts, a fall in output was recorded. This was thought to be due to impairment of venous return, as end inspiratory airway pressures achieved during hyperinflations varied between 60

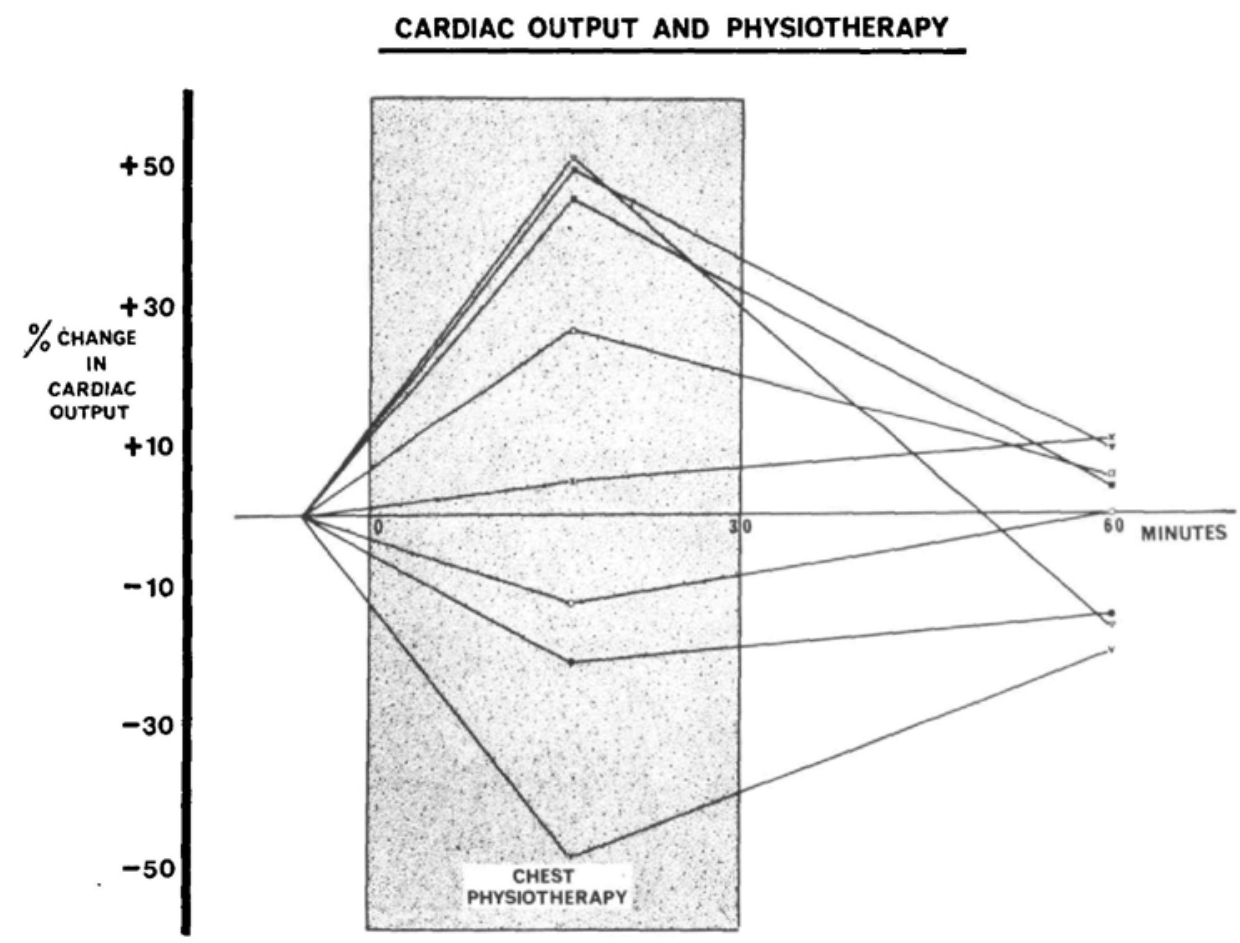

FIgURE 3. Changes in cardiac output during and following chest physiotherapy.

and $100 \mathrm{~cm} \mathrm{H}_{2} \mathrm{O}$. That these inflating pressures were not usually associated with a fall in output implicates impairment of compensatory mechanisms in those patients in whom a fall was recorded. Moreover, if oxygen consumption was not greatly changed a fall in cardiac output would produce a fall in mixed venous oxygen tensions. In the presence of existing veno-arterial shunting and of shunts likely to occur with chest compression, arterial oxygen tensions could fall to low levels. ${ }^{4}$ Patients who were conscious and who actively resisted the hyperinflations found the procedure extremely unpleasant. They became apprehensive and showed a rise in cardiac output. We attributed this to an increase in oxygen consumption with increased muscular work and a rise in circulating catecholamines.

Hyperinflations with chest compression are accompanied by such changes in cardiovascular function, without any lasting benefit to pulmonary gas exchange, 
that the indications for their use and the frequency of treatment demands assessment. Certainly lack of improvement of gas exchange following a session of chest physiotherapy should not necessarily be an indication for more frequent or more vigorous sessions. Factors other than sputum retention are often responsible for the enlarged gradients seen in patients in respiratory failure receiving artificial ventilation. It may be that after the initial sessions of physiotherapy, during the course of respiratory failure, further treatments maintain a relatively static situation and act in a prophylactic capacity. At this time maintenance of lung volume rather than sputum removal would be the relevant function of chest physiotherapy.

It is important to view the results of this study in the context in which the data was collected. It would be unreasonable to extend our conclusions to situations that have not been examined; for example, to patients with excessive sputum or to patients with pulmonary disease or to postoperative patients who are not intubated or tracheotomized. Equally, it would be unreasonable to advocate the abandonment of chest physiotherapy in the management of patients receiving artificial ventilation. But hyperinflations and chest compression are not without risk to the patient, and if these procedures do not achieve the effects expected, they should not be used. Those measures which improve pulmonary function without risk to the patient need to be defined, and chest physiotherapy can then be ordered and administered more rationally and more effectively.

\section{SUMMARY}

Six patients in respiratory failure who were receiving intermittent positive pressure ventilation were studied to determine the efficacy of chest physiotherapy and the nature of the accompanying cardiovascular changes. Arterial to alveolar tension gradients for both oxygen and carbon dioxide were measured before and after chest physiotherapy, as was cardiac output. In addition, serial cardiac output measurements were made during physiotherapy. No overall change in pulmonary gas exchange was demonstrated. Cardiovascular response varied in different patients; a rise or a fall by as much as 50 per cent of the initial cardiac output was observed. The results are discussed and it is suggested that further study is needed to define which of those procedures used during chest physiotherapy are effective and safe.

\section{RÉSUMÉ}

Nous avons étudié six malades en défaillance respiratoire qui recevaient une ventilation à pression positive intermittente pour déterminer l'efficacité de la physiothérapie thoracique et la nature des changements cardiovasculaires qui laccompagnent.

Avant et après la physiothérapie thoracique, nous avons mesuré les différences de tension alvéolaire et artérielle et de l'oxygène et du gaz carbonique de même que le débit cardiaque. De plus, nous avons fait une série de mesures du débit cardiaque au cours de la physiothérapie. La réponse cardiovasculaire a varié selon les malades; nous avons observé des variantes du débit cardiaque de 50 pour cent en 
plus ou en moins. Nous avons discuté ces résultats; nous suggérons de faire de plus amples études pour préciser quelles sont les monœuvres employées au cours de la physiothérapie thoracique qui sont à la fois efficaces et de toutes sécurité.

\section{REFERENCES}

1. OpIE, L. H. \& Spaldnc, J. M. K. Chest Physiotherapy during Intermittent Positive-Pressure Respiration. Lancet. 2: 671 (1958).

2. Holloway, R.; Desay, S. D.; Ketry, S. D.; Thambiran, A. K.; Strydom, S. E.; \& Adams, E. B. The Effect of Chest Physiotherapy on the Arterial Oxygenation of Neonates during Treatment of Tetanus by Intermittent Positive Pressure Respiration. South African Med. J. 40: 445 (1966).

3. MEAD, J.; TURner, J. M.; Mackem, P. T.; \& LitTLE, J. B. Significance of the Relationship between Lung Recoil and Maximum Expiratory Flow. J. Appl. Physiol. 22: 95 (1967).

4. FAIRLEY, H. B. \& Blentarn, G. D. Effect on Pulmonary Gas Exchange of Variations in Inspiratory Flow Rate during Intermittent Positive Pressure Ventilation. Brit. J. Anaesth. 38: 320 (1966). 